\title{
Fibrinolysis in cerebrospinal fluid after intraventricular haemorrhage
}

\author{
A Whitelaw, L Creighton, P Gaffney
}

\begin{abstract}
Concentrations of cross linked fibrin degradation products were measured in the cerebrospinal fluid from five 'normal' preterm infants (median $102 \mathrm{ng} / \mathrm{ml}$ ), four preterm infants with intraventricular haemorrhage (median $315 \mathrm{ng}$ ) $\mathrm{ml}$ ), and five infants with progressive posthaemorrhagic ventricular dilatation (median $1000 \mathrm{ng} / \mathrm{ml}$ ). Serial samples of cerebrospinal fluid from one infant showed a peak concentration two weeks after the haemorrhage.
\end{abstract}

Posthaemorrhagic ventricular dilatation(PHVD) occurs after intraventricular haemorrhage (IVH) in preterm infants and is assumed to be caused by small particles of blood clot obstructing the flow of cerebrospinal fluid through the ventricular system, basal cisterns, and arachnoid villi on the surface of the cerebral hemispheres. Little is known about the natural mechanisms by which the body clears clots from the cerebrospinal fluid. Masuda et al concluded that fibrinolytic activity started to increase three to five days after experimental intracerebral haematoma and increased for seven to 10 days, decreasing after 21 to 28 days. ${ }^{1}$ We have carried out a study to determine whether there is evidence of natural fibrinolysis in the cerebrospinal fluid after IVH.

\section{Patients and methods}

COLLECTION OF SAMPLES OF CEREBROSPINAL

FLUID

Normal preterm infants

Because of clinical instability, five preterm infants underwent lumbar puncture (one on two occasions) to exclude infection; they were subsequently found to be free from both infection and intraventricular haemorrhage. For ethical reasons completely healthy infants could not be subjected to lumbar puncture purely for research purposes.

\section{Intraventricular haemorrhage}

Four preterm infants with IVH (without PHVD) visible on cranial ultrasound scan underwent lumbar puncture to exclude infection.

\section{Intraventricular haemorrhage progressing to PHVD}

The definition of PHVD was 'ventricular width expanding after IVH to $4 \mathrm{~mm}$ over the 97 th Dr Whitelaw.

Accepted 28 February 1991 (Arch Dis (hild $1(9) 1: 66: 8(s)-8(x))$ centile' which was the same definition as that used in the multicentre trial of early tapping ${ }^{2}$ and in a textbook of neonatal neurology. ${ }^{3}$ Five preterm infants required repeated tapping to control cerebrospinal fluid pressure and excessive head growth. After the first therapeutic lumbar or ventricular tap, fluid was kept frozen for analysis of cross linked fibrin degradation products. In one infant, who had eight lumbar punctures (either for diagnostic or therapeutic purposes) a sample of fluid from each lumbar puncture was kept for analysis of concentrations of cross linked fibrin degradation products.

\section{MEASUREMENT OF FIBRINOLYTIC ACTIVITY}

Assays of cross linked fibrin degradation products

This assay was performed directly on cerebrospinal fluid using the procedure described by Gaffney $e t a l,{ }^{4}$ with the following modification. The polyvinyl plates were coated with a catcher monoclonal antibody, mab NIBn-123 (10 $\mu \mathrm{g} /$ $\mathrm{ml}$ ), which has a similar specificity to the monoclonal antibody used in the original assay; a detector (tag) polyclonal antibody to human fibrinogen (Dakopatts), which was labelled with horseradish peroxidase, was also used. Sensitivity of the assay was in the range $3-5000 \mathrm{ng} /$ $\mathrm{ml}$.

\section{Results}

The table shows that after IVH the concentra-

Median concentrations of cross linked fibrin degradation products in cerebrospinal fluid in normal infants and those with IVH and PHVD

\begin{tabular}{llcc}
\hline & $\begin{array}{l}\text { No of } \\
\text { infants }\end{array}$ & \multicolumn{2}{l}{$\begin{array}{l}\text { Cross linked fibrin } \\
\text { degradation } \\
(\text { ng/ml })\end{array}$} \\
\cline { 2 - 4 } & & Median & Range \\
\hline Normal preterm infants & 5 & 102 & $20-252$ \\
IVH & 4 & 315 & $280-410$ \\
PHVD & 5 & 1000 & $405-5000$ \\
\hline
\end{tabular}

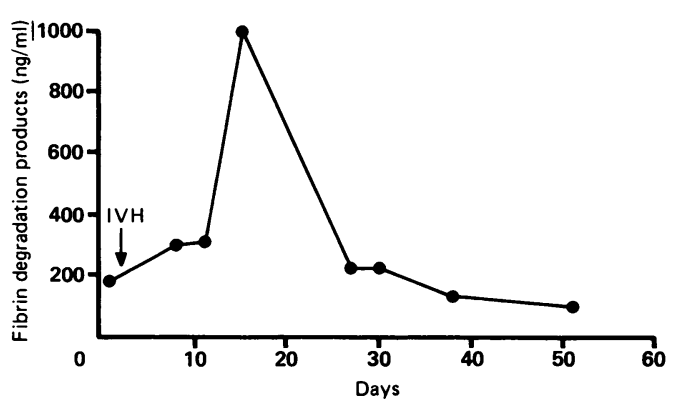

Serial concentrations of cross linked fibrin degradation products in the cerebrospinal fluid of an infant who developed posthaemorrhagic ventricular dilatation and was treated by serial tapping. 
tions of cross linked fibrin degradation products were considerably higher than in the 'normal' preterm infants. In the five infants who developed PHVD, the concentrations were even higher than in those with haemorrhage alone. The figure shows the serial concentrations in an infant who developed PHVD after IVH, which resolved after repeated lumbar punctures. It can be seen that the concentrations peaked at about two weeks.

\section{Discussion}

These preliminary investigations show that preterm infants actively attempt to lyse blood clot in the cerebrospinal fluid. There is some evidence of fibrinolytic activity in 'normal' infants but this is increased in those who have had an intraventricular haemorrhage. Larger haemorrhages that lead on to ventricular dilatation seem to elicit a greater fibrinolytic response.
The peak of fibrinolysis after about two weeks in the infant whose results are shown in the figure confirms the fibrinolytic peak found by Masuda $e t$ al. ${ }^{1}$ We found no evidence to suggest that the infants who developed PHVD had decreased fibrinolytic activity.

We are currently investigating the possibility of preventing PHVD by increasing intraventricular fibrinolysis.

1 Masuda T, Dohrmann GJ, Kwaan HC, Erickson RK, Wollman RL. Fibrinolytic activity in experimental intracerebral hematoma. $\mathcal{F}$ Neurosurg 1988;68:274-8.

2 Ventriculomegaly Trial Group. Randomised trial of early tapping in neonatal posthaemorrhagic ventricular dilatatapping in neonatal posthaemorr
tion. Arch Dis Child 1990;65:3-10.

3 De Vries LS, Larroche JC, Levene MI. Intracranial sequelae. In: Levene MI, Bennett MJ, Punt J, eds. Fetal and neonatal neurology and neurosurgery. Edinburgh: Churchill Livingstone, 1988:346-52.

4 Gaffney PJ, Creighton LJ, Perry MJ, Callus M, Thorpe R, Spitz M. Monoclonal antibodies to crosslinked fibrin degradation products (XL FDP). Br $\mathcal{F}$ Haematol 1988;68: 83-90. 